\title{
ADSORÇÃO DE ÁCIDOS GRAXOS LIVRES PRESENTES EM BIOCOMBUSTÍVEIS EMPREGANDO LAMA VERMELHA E ALUMINA ATIVADAS TERMICAMENTE COMO ADSORVENTES
}

H. S. CORREA ${ }^{1}$, K. M. B. da $\operatorname{COSTA}^{2}$, M. L. dos $\operatorname{SANTOS}^{1}$, J. H. M. dos $\operatorname{SANTOS}^{1}$, A. A. $\mathrm{MANCIO}^{3}$, S. A. P. MOTA ${ }^{4}$, N. T. MACHADO

${ }^{1}$ Universidade Federal do Pará, Discente da Faculdade de Engenharia Química

${ }^{2}$ Universidade Federal do Pará, Discente do Programa de Pós-Graduação de Engenharia Química(PPGEQ)

${ }^{3}$ Universidade Federal do Pará, Discente do Programa de Pós-Graduação em Engenharia de Recursos Naturais da Amazônia(PRODERNA)

${ }^{4}$ Universidade Federal do Sul e Sudeste do Pará, Docente da Faculdade de Engenharia de Materiais

${ }^{5}$ Universidade Federal do Pará, Docente da Faculdade de Engenharia Química E-mail para contato: okamishin@gmail.com

RESUMO - O presente trabalho teve como objetivo investigar o efeito de três variáveis de processo (efeito do teor inicial de ácidos, efeito do adsorvente e efeito da porcentagem de adsorvente) sobre a adsorção de ácidos presentes nas frações destiladas derivadas do Produto Líquido Orgânico (PLO) obtido por craqueamento termocatalítico de óleos vegetais. Os resultados mostram que o um incremento no teor de AGL favoreceu um aumento da taxa inicial de adsorção de AGLs, quando colocadas em contato com 5\% de alumina ativada e, desfavoreceu um aumento da taxa inicial de adsorção de AGLs presentes nas frações destiladas, quando colocadas em contato com $1 \%$ de alumina ativada. Ambos os adsorventes empregados foram capazes de remover os AGLs, sendo que os melhores resultados no presente estudo foram alcançados quando se utilizou $1 \%$ de lama vermelha ativada e $1 \%$ de alumina ativada, resultando em 25,9287 mg AGLs adsorvidos/g de adsorvente e 12,9661 mg AGLs adsorvidos/g de adsorvente, respectivamente.

\section{INTRODUÇÃO}

O processo de craqueamento de óleos vegetais ou gorduras animais ocorrem em dois estágios sucessivos e distintos. O primeiro estágio, conhecido como craqueamento primário, é caracterizado pela formação de espécies ácidas através da decomposição das moléculas de triglicerídeos que ocorrem através da quebra de ligações $\mathrm{C}-\mathrm{O}$ dentro da parte glicerídica da cadeia do triglicerídeo. O segundo estágio é caracterizado pela degradação de ácidos produzidos no primeiro estágio levando a formação de hidrocarbonetos com propriedades similares aqueles produtos do petróleo. Este estágio é chamado de craqueamento secundário (PRADO e ANTONIOSI FILHO, 2009). 


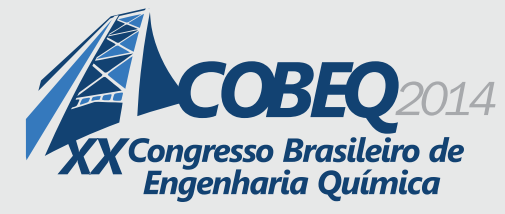

Os produtos obtidos por craqueamento térmico catalítico apresentam menores quantidades de compostos ácidos. Portanto, o catalisador apresenta atividade no processo de craqueamento secundário, em que os ácidos graxos decompõem-se para formar hidrocarbonetos (PRADO e ANTONIOSI FILHO 2009). Porém, apesar do craqueamento térmico catalítico produzir biocombustíveis com menores níveis de acidez, o que se tem observado na literatura é que mesmo na presença de catalisadores, o craqueamento térmico catalítico não reduz a acidez para valores satisfatórios, como pode ser constatado na Tabela 1 .

Tabela 1 - Índice de acidez dos produtos obtidos no processo de craqueamento em diferentes condições

\begin{tabular}{cccc}
\hline \multirow{2}{*}{ Sistema usado } & $\begin{array}{c}\text { Índice de acidez } \\
(\mathrm{mg} \mathrm{KOH} / \mathrm{g})\end{array}$ & $\begin{array}{c}\text { Quantidade de } \\
\text { catalisador }\end{array}$ & $\begin{array}{c}\text { Índice de acidez } \\
\text { (mg KOH/g) }\end{array}$ \\
\cline { 2 - 3 } & Biocombustível bruto & & Biocombustível bruto \\
\hline $\begin{array}{c}\text { Craqueamento simples } \\
\text { Craqueamento simples } \\
\text { modificado }\end{array}$ & 90,8 & $10 \%$ de bauxita & 44,6 \\
Craqueamento fracionado & 44,6 & $20 \%$ de bauxita & 35,0 \\
\hline
\end{tabular}

Fonte: PRADO e ANTONIOSI FILHO (2009).

A maioria das formas propostas para resolver ou minimizar o problema da elevada acidez dos biocombustíveis ainda esta baseada em intervenções empíricas focadas sobre situações particulares. As soluções propostas incluem o uso de blends de óleos, substituição do material do equipamento (atualmente, a forma mais usada e menos onerosa para reduzir a corrosão), injeção local de inibidores e a remoção de ácidos naftênicos por extração ou adsorção (SILVA et al., 2013).

A adsorção é uma potencial solução de baixo custo e também tem mostrado capacidade de remover os ácidos naftênicos presentes em combustíveis derivado do petróleo. Zeolitas, aluminosilicatos a partir do resíduo proveniente do processo de fabricação de catalisadores, sílica gel, argilas, alumina, mistura de óxidos de magnésio e alumínio, e resinas de troca iônica foram propostos como adsorventes para ácidos naftênicos, uma vez que esses ácidos podem ser recuperados usando solventes polares como cetonas e alcoóis (SILVA et al., 2013).

Existem alguns materiais com grande potencial de adsorção, entre estes se encontra a lama vermelha, um resíduo gerado em grande escala no processo de fabricação de alumínio. Este resíduo, quando adequadamente tratado (térmica ou quimicamente) apresenta propriedades de adsorção promissoras (WANG et al., 2008), podendo viabilizar sua aplicação na remoção de ácidos graxos livres presentes em biocombustíveis. Assim, a ideia é que as propriedades dos biocombustíveis melhorados por adsorção, isto é, sem a presença de ácidos, estariam muito mais perto da alimentação de hidrocarbonetos típicos do que o biocombustível original, e assim, o mesmo protocolo analítico aplicado para as alimentações das refinarias de petróleo poderiam ser usadas. (OASMAA; ELLIOTT; KORHONEN, 2010). 


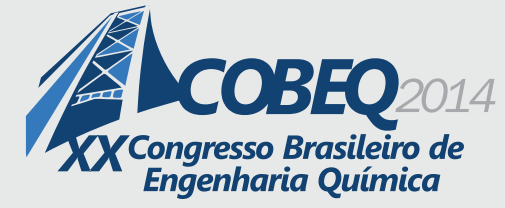

A alumina sem tratamento não apresenta as características necessárias para um bom adsorvente. Porém, quando ativada termicamente apresenta um aumento no número de poros e área superficial específica, o que favorece o seu desempenho no processo de adsorção (OLIVEIRA, 2005). O aumento da área superficial do adsorvente alumina obtido por meio da ativação térmica ocorre devido à remoção das hidroxilas sob a forma de moléculas de água, presentes no Hidróxido de Alumínio (AMARAL, 2013).

Neste contexto, o presente trabalho tem como objetivo principal avaliar o efeito da concentração inicial de ácidos graxos livres, isto é, da alimentação (frações destiladas proveniente do produto líquido orgânico produzido por craqueamento térmico catalítico do óleo de palma) e o efeito da porcentagem ( $1 \%$ e $5 \%)$ de dois adsorventes, lama vermelha ativada a $400^{\circ} \mathrm{C}$ e alumina ativada, sobre a adsorção dos ácidos graxos livres.

\section{MATERIAIS E MÉTODOS}

\subsection{Adsorventes}

Os adsorventes empregados no presente trabalho foram lama vermelha in natura e alumina, que foram cedidos pela empresa ALUNORTE (Alumina do Norte do Brasil S/A). Para que a lama vermelha e a alumina fossem utilizadas como adsorventes, realizou-se algumas etapas de pré-tratamento conforme descritas a seguir.

Lama vermelha ativada (LV): (1) Secagem da lama vermelha in natura - a secagem da lama vermelha foi realizada em estufa de recirculação de por $24 \mathrm{~h}$ a $110^{\circ} \mathrm{C}$; (2) Desagregação da lama vermelha seca - após a secagem, aproximadamente $2^{\circ} \mathrm{kg}$ de lama vermelha seca foi submetida a uma etapa de desagregação em um moinho de bolas por um período de 30 minutos; (3) Ativação térmica - após a lama vermelha ter passado por uma etapa de secagem e desagregação, $750^{\circ} \mathrm{g}$ de lama vermelha seca e desagregada foi submetida a ativação térmica a $400^{\circ} \mathrm{C}$. A ativação térmica da lama vermelha foi realizada em um forno (Químis, São PauloBrasil, Modelo:Q.318.24) por um período de $4^{\circ} \mathrm{h}$ e taxa de aquecimento de $5^{\circ} \mathrm{C} / \mathrm{min}$.

Alumina ativada (AA): baseado no método descrito por Cunha et al. (2012), inicialmente, as amostras (aproximadamente $500 \mathrm{~g}$ ) de Hidróxido de Alumínio $\left(\mathrm{Al}(\mathrm{OH})_{3}\right)$, o precursor do adsorvente, foram lavadas em água a aproximadamente $100^{\circ} \mathrm{C}$ sob agitação em Becker de $100 \mathrm{~mL}$ durante uma hora, objetivando-se remover o teor de Hidróxido de sódio residual e outras impurezas indesejáveis. Em seguida, as amostras de Hidróxido de Alumínio $\left(\mathrm{Al}(\mathrm{OH})_{3}\right)$ úmidas foram submetidas a secagem a $105^{\circ} \mathrm{C}$, por um período de 24 horas, em estufa com recirculação de ar (Fabbe, São Paulo- Brazil, Modelo 179), sendo posteriormente armazenadas em dessecadores. A ativação térmica do Hidróxido de Alumínio $\left(\mathrm{Al}(\mathrm{OH})_{3}\right)$ foi realizada à temperatura de $450^{\circ} \mathrm{C}$ em forno elétrico (Químis, São PauloBrasil, Modelo:Q.318.24), com controle digital de temperatura, rampa e taxa de aquecimento, durante duas horas. 


\subsection{Fração destilada}

As frações destiladas usadas neste trabalho adotadas como alimentação foram obtidas no Laboratório de Processos de Separações Térmicas (THERMTEK/FEQ/ITEC/UFPA) através da destilação a pressão atmosférica (coluna de destilação piloto) do Produto Líquido Orgânico produzido por craqueamento termocatalítico do óleo de palma. Para o desenvolvimento do presente estudo foram selecionadas duas frações destiladas na faixa de temperatura de 305$400^{\circ} \mathrm{C}$, as quais cada uma das frações apresentava um teor de ácido graxo livre diferente, conforme apresentado na Tabela 2, com o objetivo de avaliar o efeito do teor de ácido graxo livre inicial (da alimentação) sobre a adsorção dos mesmos.

Tabela 2 - Número de ácidos totais das frações destiladas na faixa de temperatura de $305-400{ }^{\circ} \mathrm{C}$ destinadas a desacidificação por adsorção

\begin{tabular}{cc}
\hline Alimentação & NAT (mg KOH/g) \\
\hline A & 1,5547 \\
B & 19,6470 \\
\hline
\end{tabular}

\subsection{Cinética de adsorção dos ácidos graxos livres}

No presente estudo de desacidificação por adsorção das frações destiladas, as seguintes variáveis de processo foram alteradas: (1) teor de ácidos graxos livres presente na alimentação (frações destiladas); (2) adsorvente; (3) porcentagem de adsorvente e (4) tempo de contato (cinética de adsorção). As condições experimentais mantidas constantes foram temperatura ambiente, pressão atmosférica, velocidade de agitação de $160 \mathrm{rpm}$.

Efeito do teor de ácidos graxos livres: com o objetivo de avaliar o efeito do teor de ácidos graxos livres presentes na alimentação sobre o processo de desacidificação por adsorção, foram selecionadas duas frações destiladas, A e B, com número de ácidos totais diferentes.

Efeito do adsorvente: com o objetivo de avaliar o efeito da desacidificação por adsorção, foram selecionados dois adsorventes diferentes: lama vermelha ativada e alumina ativada.

Efeito da porcentagem de adsorvente: com o objetivo de avaliar o efeito da porcentagem de adsorvente sobre o processo adsorção de ácidos graxos livres, duas porcentagens de adsorvente foram selecionadas, 1 e $5 \%$.

Cinética de adsorção: Os experimentos de cinética de adsorção dos ácidos graxos livres foram realizados no sistema de batelada em frascos erlenmeyer de $250 \mathrm{~mL}$, os quais foram dispostos em uma mesa agitadora (AGIF/RES-MCT-010/Ética/Q-842-210) com agitação orbital para que as frações destiladas tivessem o contato adequado com o adsorvente. Cinco gramas de fração destilada e a porcentagem pré-estabelecida acima de adsorvente foram adicionados em cada erlenmeyer e, em seguida, agitou-se por tempos de contato pré-estabelecidos. $(0 ; 2,5 ; 5 ; 10$; $20 ; 30 ; 40 ; 50 ;$ e 60$)$ a fim de se obter cinéticas de adsorção. Após o procedimento de adsorção, o conteúdo do frasco foi submetido à filtração a vácuo, empregando papel filtro Whatman $\mathrm{n}^{\circ} 1$, 


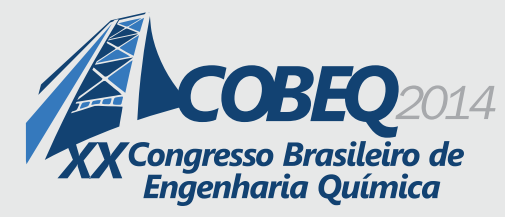

obtendo-se como parte filtrada uma fração destilada desacidificada, a qual foi determinada o número de ácidos totais de acordo com o método padrão da ASTM D 974.

A avaliação da quantidade relativa de ácidos graxos livres removidos foi realizada através e titulação colorimétrica, em que foi utilizado o método padrão da ASTM D 974 para determinar o número de ácidos totais (NAT) antes e depois da adsorção.

\section{RESULTADOS E DISCUSSÃO}

As Tabelas 3 e 4 e as Figuras 1, 2 e 3 apresentam os resultados da cinética de adsorção dos ácidos graxos livres. Os resultados apresentados estão relacionados à quantidade relativa de ácidos graxos livres adsorvidos nos diferentes tempos de contato dos experimentos feitos com duas alimentações (frações destiladas na faixa de temperatura de $305-400^{\circ} \mathrm{C}$ ) distintas em relação ao teor de ácidos graxos livres, onde através destes resultados podemos verificar o efeito de três variáveis de processo sobre a remoção dos AGLs.

Tabela 3 - Quantidade relativa de ácidos graxos livres adsorvidos em função do tempo de contato da alimentação com o adsorvente (alumina ativada)

\begin{tabular}{ccccc}
\hline \multirow{2}{*}{\begin{tabular}{c} 
Tempo de contato $($ min) \\
\cline { 2 - 5 }
\end{tabular}} & \multicolumn{4}{c}{ mg de AGL adsorvidos/g de adsorvente } \\
\cline { 2 - 5 } & A & B & A $\%$ de alumina ativada \\
\hline 0 & 0,0000 & 0,0000 & 0,0000 & B ativada \\
2,5 & 9,5165 & 4,5217 & 0,4384 & 18,4193 \\
5 & 10,1387 & 5,0400 & 3,4872 & 19,6791 \\
10 & 9,8735 & 8,6871 & 3,6766 & 20,0405 \\
20 & 10,1541 & 7,8690 & 4,2452 & 18,8236 \\
30 & 15,4173 & 5,9327 & 4,0356 & 22,4576 \\
40 & 20,6811 & - & 4,2928 & 19,6215 \\
50 & 25,9287 & - & 3,8308 & 20,5426 \\
60 & 25,6322 & - & 4,1570 & 22,6895 \\
\hline
\end{tabular}

Alimentação: A = 1,5547 mg KOH/g; B = 19,6470 mg KOH/g.

A partir dos resultados dispostos na Tabela 3 e Figura 1, observou-se que a quantidade relativa de AGLs adsorvidos aumenta com o tempo, alcançando uma quantidade máxima na cinética de adsorção, e depois de um determinado tempo de contato verifica-se que a quantidade relativa de AGLs adsorvidos se mantém praticamente constante para a alimentação A com 5\% de alumina ativada, indicando que o equilíbrio de adsorção foi alcançado. Assim, o tempo de contato necessário para alcançar o equilíbrio de adsorção dos AGLs presentes nas frações destiladas foi de 10 min para a alimentação A. Para as alimentações A ( $1 \%$ de LV), B ( $1 \%$ de AA) e B ( $5 \%$ de LV), não foi possível observar o tempo de contato necessário para alcançar o equilíbrio de adsorção, pois tanto para a alimentação A ( $1 \%$ de LV) como para a alimentação B ( $5 \%$ de LV), verificou-se que a quantidade de ácidos graxos livres adsorvidos continuou aumentando, até o final do tempo predefinido (60 min), com o aumento do tempo de contado entre adsorvente e alimentação. Isso indica que ambas as alimentações, nas referidas condições, necessitam de um tempo de contato superior ao investigado no 
presente trabalho para alcançar o equilíbrio de adsorção.

Tabela 4 - Quantidade relativa de ácidos graxos livres adsorvidos em função do tempo de contato da alimentação A com o adsorvente (lama vermelha ativada)

\begin{tabular}{ccc}
\hline \multirow{2}{*}{ Tempo de contato $(\mathrm{min})$} & \multicolumn{2}{c}{ mg de AGL adsorvidos/g de adsorvente } \\
\cline { 2 - 3 } & 1\% de LV ativada & $5 \%$ de LV ativada \\
\hline 0 & 0,0000 & 0,0000 \\
5 & 13,7066 & 4,1730 \\
10 & 13,4641 & 3,0375 \\
20 & 12,9541 & 1,1954 \\
30 & 12,9661 & 2,0836 \\
40 & 12,8088 & 4,2590 \\
50 & 12,9260 & 4,1445 \\
60 & 11,8920 & 4,7082 \\
\end{tabular}

Alimentação: A = 1,5547 mg KOH/g.

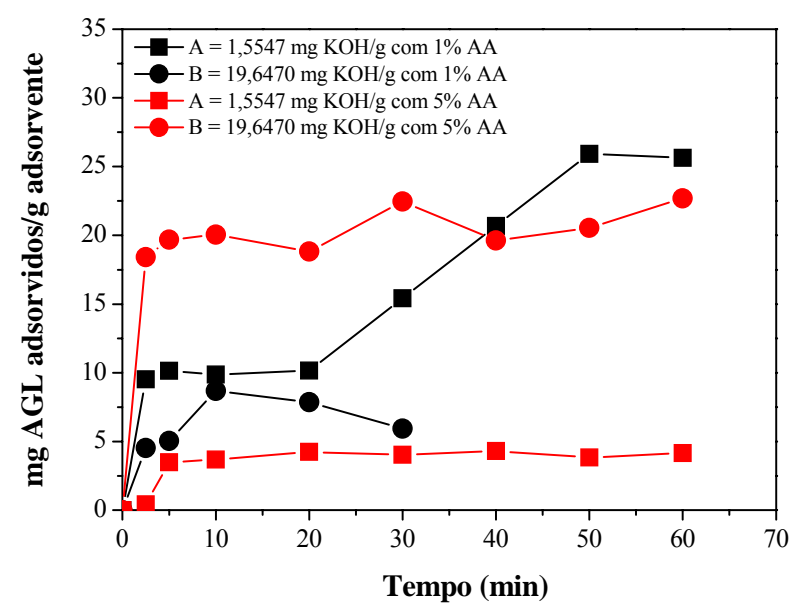

Figura 1 - Cinética de adsorção de ácidos graxos livres da alimentação A e B com alumina ativada (AA).

\subsection{Efeito do teor de ácidos graxos livres}

Ainda em relação a Figura 1 para as alimentações A e B, verificou-se que o um incremento no teor de AGL favoreceu um aumento da taxa inicial de adsorção dos ácidos graxos livres presentes nas frações destiladas, quando colocadas em contato com 5\% de alumina ativada. Este fato, isto é, o aumento da taxa inicial de adsorção com a elevação da concentração inicial também foi constatado por Silva (2010) em seu trabalho de adsorção de ácidos orgânicos passíveis de produção por via fermentativa e de relevância em petroquímica verde, empregando carvão ativado e resinas poliméricas como adsorventes e, por Lin e Lin (2005) que investigaram a cinética de adsorção de ácidos AGL residuais a partir de óleo de soja degomado com água e óleo de soja refinado com uma base, 


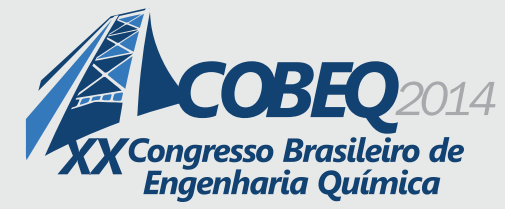

19 a 22 de outubro de 2014

Florianópolis/SC

empregando argila regenerada. No entanto, observou-se que o um incremento no teor de AGL não favoreceu um aumento sobre a taxa inicial de adsorção dos ácidos graxos livres presentes nas frações destiladas, quando colocadas em contato com $1 \%$ de alumina ativada. Na verdade, verificou-se o efeito inverso.

\subsection{Efeito do adsorvente e da porcentagem de adsorvente}

Quando se compara o tipo de adsorvente empregado na remoção de ácidos graxos livres por adsorção de uma fração destilada com baixos teores de AGLs, verifica-se através da Figura 2, que as curvas de cinética de adsorção dos AGLs sao muito similares quando 5\% de adsorvente, independente se o adsorvente é lama vermelha ativada ou alumina ativada, sem podermos inferir qual foi melhor neste aspecto. Porém, quando apenas $1 \%$ de adsorvente é empregado, verifica-se outro comportamento, onde nos primeiros 20 minutos a lama vermelha ativada é mais eficiente do que a alumina ativada e, nos minutos restantes, isto é, de 20 a 60 minutos, a alumina ativada se destaca na adsorção de ácidos saindo de $10 \mathrm{mg}$ de AGLs adsorvidos/g para um pouco mais de $25 \mathrm{mg}$ de AGLs adsorvidos/g de adsorvente, sendo este o melhor resultado obtido no presente estudo.

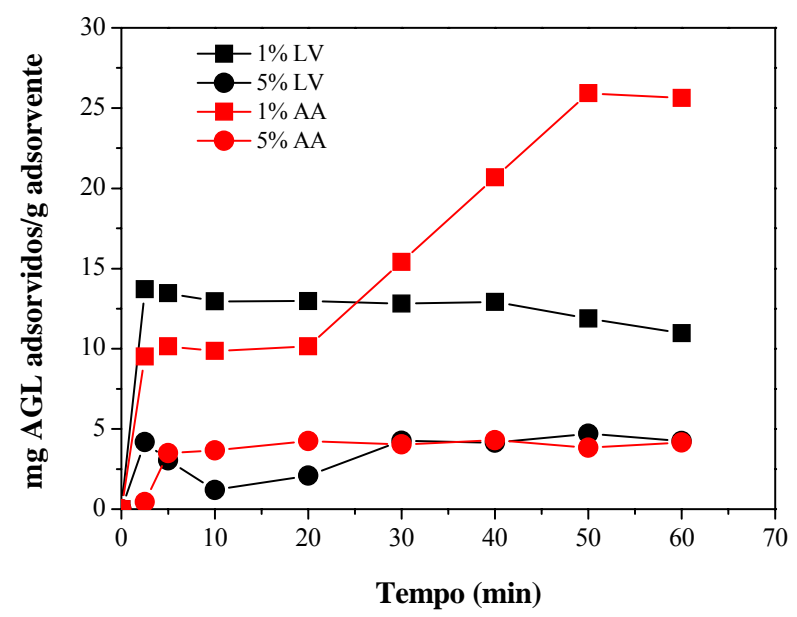

Figura 1 - Cinética de adsorção de ácidos graxos livres da alimentação A para lama vermelha ativada e alumina ativada (AA).

\subsection{Efeito da porcentagem de adsorvente}

De acordo com a Figura 2, foi observado para ambos os adsorventes empregados no presente trabalho, que quando há um aumento na porcentagem de adsorvente há uma redução na quantidade de ácidos graxos livres adsorvidos pelos mesmos, indicando que a capacidade de adsorção foi reduzida tanto para lama vermelha ativada como para alumina ativada. Amaral (2013) explica este comportamento relatando que, embora, uma quantidade maior de sítios ativos, por parte do adsorvente, esteja disponível com o aumento da porcentagem de adsorvente em relação à massa de alimentação, a área especifica (área por unidade de massa) não é alterada. Portanto, os melhores 


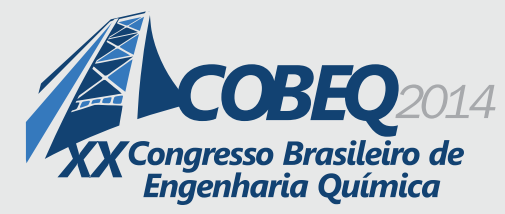

resultados no presente estudo, foram alcançados quando se utilizou $1 \%$ de lama vermelha ativada e $1 \%$ de alumina ativada, resultando em 25,9287 mg AGLs adsorvidos/g de adsorvente e 12,9661 mg AGLs adsorvidos/g de adsorvente, respectivamente.

\section{CONCLUSÃO}

De acordo com os resultados apresentados acima, foi possível determinar o tempo necessário para alcançar o equilíbrio de adsorção de AGLs apenas para a alimentação A com $5 \%$ de alumina ativada, o qual foi de $10 \mathrm{~min}$. Além disso, verificou-se que o um incremento no teor de AGL favoreceu um aumento da taxa inicial de adsorção dos ácidos graxos livres presentes nas frações destiladas, quando colocadas em contato com $5 \%$ de alumina ativada. No entanto, observou-se que o um incremento no teor de AGL não favoreceu um aumento da taxa inicial de adsorção dos ácidos graxos livres presentes nas frações destiladas, quando colocadas em contato com $1 \%$ de alumina ativada. Ambos os adsorventes empregados foram capazes de remover os ácidos graxos livres (AGL) de frações destiladas, com diferentes teores de ácidos, provenientes do produto líquido orgânico. Por último, foi observado para ambos os adsorventes empregados no presente trabalho, que quando houve um aumento na porcentagem de adsorvente, a capacidade de adsorção foi reduzida tanto para lama vermelha ativada como para alumina ativada. Os melhores resultados no presente estudo, foram alcançados quando se utilizou $1 \%$ de lama vermelha ativada e $1 \%$ de alumina ativada, resultando em 25,9287 mg AGLs adsorvidos/g de adsorvente e 12,9661 mg AGLs adsorvidos/g de adsorvente, respectivamente.

\section{REFERÊNCIAS}

AMARAL, A. R. Estudo Cinético e das Isotermas de Adsorção dos Óleos de Palma (Elaies guineenses, Jacq.) e Andiroba (Carapa guianensis, Aubl.) em $\gamma$-Alumina e Modelagem da Dessorção com Dióxido de Carbono Supercrítico. 2013. 145 f. Dissertação (Mestrado em Engenharia Química). Universidade Federal do Pará, Belém, 2013.

OASMAA, A.; ELLIOTT, D. C.; KORHONEN, J. Acidity of Biomass Fast Pyrolysis Bio-oils. Energy Fuels. V. 24, pag. 6548-6554, 2010.

OLIVEIRA, L. B.; ANGÉLICA, R. S.; NEVES, R. F.; FIGUEIREDO, B.R. Avaliação da Adsorção do Íon As(V) em Solução sobre Alumina Ativada, Rejeitos de Caulim e seus Produtos de Transformação. Workshop Internacional em Geologia Médica, 2005.

PRADO, C.M.R.; ANTONIOSI FILHO N. R. Production and characterization of the biofuels obtained by thermal cracking and thermal catalytic cracking of vegetable oils. J. Anal. Appl. Pyrolysis. V. 86, pag. 338-347, 2009.

SILVA, A. H. Estudos de adsorção de ácidos orgânicos visando sua recuperação de meios fermentados. 2010. 134 f. Dissertação. (Mestrado em Engenharia Química) Universidade Estadual de Campinas, Campinas, 2010.

SILVA, J. P.; COSTA, A. L. H.; CHIARO, S. S. X.; DELGADO, B. E. P. C.; FIGUEIREDO, M. A. G.; SENNA, L. F. Carboxylic acid removal from model petroleum fractions by a commercial clay adsorbent. Fuel Processing Technology. V. 112, pag. 57-63, 2013.

WANG, S.; ANG, H.M.; TADÉ, M.O. Novel applications of red mud as coagulant, adsorbent and catalyst for environmentally benign processes. Chemosphere. V. 72, p. 1621-1635, 2008. 